\title{
Radiological and histopathological evaluation of experimentally-induced periapical lesion in rats
}

\author{
Renata Cordeiro TEIXEIRA¹, Cassia Maria Fischer RUBIRA ${ }^{1}$, Gerson Francisco ASSIS ${ }^{2}$, José Roberto Pereira LAURIS ${ }^{3}$, \\ Tania Mary CESTARI ${ }^{4}$, Izabel Regina Fischer RUBIRA-BULLEN ${ }^{5}$

\begin{abstract}
1- DDS, MSc, PhD, Department of Stomatology, Bauru School of Dentistry, University of São Paulo, Bauru, SP, Brazil.
3- PhD, Associate Professor, Department of of Pediatric Dentistry, Orthodontics and Community Health, Bauru School of Dentistry, University of São Paulo, Bauru, SP, Brazil.

4- PhD, Department of Biological Sciences, Bauru School of Dentistry, University of São Paulo, Bauru, SP, Brazil.

5- DDS, MSc, PhD, Associate Professor, Department of Stomatology, Bauru School of Dentistry, University of São Paulo, Bauru, SP, Brazil.
\end{abstract} \\ 2- PhD, Associate Professor, Department of Biological Sciences, Bauru School of Dentistry, University of São Paulo, Bauru, SP, Brazil.
}

Corresponding address: Renata Cordeiro Teixeira - Faculdade de Odontologia de Bauru - FOB/USP - Departamento de Estomatologia - Al. Dr. Octávio Pinheiro Brizolla, 9-75 - 17012-901 - Bauru - SP - Brazil - e-mail: rena@usp.br

Received: September 21, 2009 - Modification: April 29, 2010 - Accepted: May 25, 2010

\section{ABSTRACT}

\begin{abstract}
$\mathrm{O}$ bjective: This study evaluated experimentally-induced periapical bone loss sites using digital radiographic and histopathologic parameters. Material and Methods: Twentyseven Wistar rats were submitted to coronal opening of their mandibular right first molars. They were radiographed at 2, 15 and 30 days after the operative procedure by two digital radiographic storage phosphor plates (Digora ${ }^{\circledR}$ ). The images were analyzed by creating a region of interest at the periapical region of each tooth (ImageJ) and registering the corresponding pixel values. After the sacrifice, the specimens were submitted to microscopic analysis in order to confirm the pulpal and periapical status of the tooth. Results: There was significant statistically difference between the control and test sides in all the experimental periods regarding the pixel values (two-way ANOVA; $p<0.05$ ). Conclusions: The microscopic analysis proved that a periapical disease development occurred during the experimental periods with an evolution from pulpal necrosis to periapical bone resorption.
\end{abstract}

Key words: Radiology. Periapical diseases. Histology. Rats.

\section{INTRODUCTION}

Digital intraoral radiographic systems have several advantages compared with conventional film-based radiography. These advantages, in Endodontics, include the potential of a lower radiation exposure to the patient and faster image display ${ }^{25}$. Moreover, it was introduced the opportunity of evaluating the progression of periapical bone loss by digital tools as the pixel values $^{3,15}$.

Radiographs do not always reflect the extent of the destructive process in the periapical tissues and generally under-represent the size of a lesion ${ }^{12}$. Studies have suggested that pathologic involvement of the cortical plate, or at least junctional trabeculae, is a prerequisite for radiographic detection of periapical pathoses ${ }^{16}$. Nevertheless, periapical lesions confined to cancellous bone could be detected radiographically using pixel values using one of the tools of the digital image, the histogram². Only a few studies employing animal models ${ }^{3,7,8}$ or human biopsies ${ }^{10,21,23}$ have compared the diagnostic and quantifying accuracy of radiographs to the gold standard represented by the histology. The aim of this study was to induce periapical disease in rats to assess the pixel values in different experimental periods to evaluate the bone loss progression.

\section{MATERIAL AND METHODS}

\section{General and radiographic procedures}

This study was approved by the Animal Research Ethics Committee of the Bauru School of Dentistry, University of São Paulo. The experimental groups were composed of 27 Wistar rats (Rattus novergicus), divided into three groups with nine animals each, according to the sacrifice date, Group 
1: 2 days, Group 2: 15 days, Group 3: 30 days $^{6}$. The animals were submitted to general intramuscular anesthesia. In each animal, a cavity was made on the occlusal face of the mandibular first molar on the right side with a spherical burr size $1 / 4$, at high speed without cooling ${ }^{28}$. The left side was set as control.

\section{Radiographic analysis}

The material for study was obtained after euthanizing the animal with an anesthetic overdose. The right and left hemi-mandibles of each rat were separated and radiographed with two phosphor plates (PSPs/ Digora-Soredex-Tuusula, Finland). The exposition was performed according to the parameters: $70 \mathrm{kVp}, 7 \mathrm{~mA}$, focus-film distance of 30 $\mathrm{cm}$, exposure time of $0.09 \mathrm{~s}$. A standard aluminum stepwedge was set in each image, and an acrylic plate measuring $0.3 \times 0.4 \times 0.2 \mathrm{~cm}$ was positioned over the hemi-mandibles to simulate soft tissue. The stepwedge was used as a standard image technique, which is essential for control of day-today variations in the sensitivity of the detector ${ }^{29}$.

The radiographic evaluation was performed using the public domain software Image $\mathrm{J}$ (version $1.33 \mu$, National Institute of Health, Washington, DC) A region of interest (ROI/252 pixels) was opened in the periapical region of the every tooth, closest to the mesial root, without touching it. Only the periapical bone was enclosed in the ROI. Using the histogram tool, the pixel values of the ROIs were established. The normalized pixel values of the images (NPI) were then obtained by using the following equation ${ }^{29}$ : NPI=PI/CR. Where PI is the mean pixel intensity of the ROI, and CR is the pixel intensity of the ROI of the standard aluminum stepwedge. The pixel value of zero corresponded to black and the pixel value of 255 to white.

\section{Histomorphometrical analysis}

Hemi-mandibles were fixed in formalin $10 \%$, decalcified in EDTA and processed histologically. Five semi-serial sections of each hemi-mandible with $5 \mu \mathrm{m}$ thickness were cut and stained with hematoxylin and eosin. All histological sections were identified with a random numerical sequence and periapical tissues were histomorphometrically analyzed for both test and control sites. In the test site it was noted whether the tooth had pulpitis, necrosis or presented any sign of inflammation, and whether or not there was presence of periapical bone resorption. The percentages of bone tissue in the apical region of the root, soft tissue (connective tissue and inflammatory infiltrate, when present), bone marrow and inferior alveolar nerve were obtained in a digital image analysis system, composed of a Zeiss Axioskop II microscope, CCDIRIS RGB - Sony camera (Sony DXC-151A RGB Video Camera-Sony Corporation, Tokyo, Japan) and Kontron $\mathrm{KS} 300^{\circledR}$ software (Kontron Electronic GMBM, Munich, Germany). For this purpose, an image was captured at $10 x$ objective from each histologic slice, which contained the apical portion of the mesial root perpendicular to the alveolar nerve, positioned centrally. The studied area was established in numbers of pixels. Each image captured had 307,200 pixels and evaluated total area was 1536,000 pixels. The area (in pixels) was measured to quantify the area occupied by bone tissue in the apical region of the root, soft tissue (connective tissue and inflammatory infiltrate, when present), bone marrow and inferior alveolar nerve.

\section{RESULTS}

\section{Radiographic analysis}

The radiographic analysis showed that the pixel values in the three experimental periods increased on the test side in comparison with the control side, indicating bone loss in a similar manner both PSPs plates used. The Student's T test showed a statistically significant difference between control and test sites for the three groups tested $(p<0.05)$ (Table 1 ). The influence of the time on periapical disease was studied using one-way ANOVA and Tukey's tests. ANOVA showed no statistically significant variation for any of the time intervals in Plate $1(p>0.05)$, as well as for the control side of Plate 2 ( $p>0.05)$. This variation was only shown to be significant in Plate $2(p<0.05)$ between the test groups 2 and 3 (Figures $1 \mathrm{~A}, \mathrm{D}, \mathrm{G}, \mathrm{J}$ ).

Table 1- Means and standard deviation of the pixel values on the test and control sides for the Digora $₫$ system phosphorus plates 1 and 2, in the rats of Groups I, II and III

\begin{tabular}{lcccc}
\hline & \multicolumn{4}{c}{ Mean of pixel values } \\
& Test - Plate I & Control - Plate I & Test - Plate II & Control - Plate II \\
\hline Group I & $191.88^{*} \pm 4.234^{* *}$ & $184.17 \pm 4.197$ & $188.86 \pm 4.186$ & $179.40 \pm 4.180$ \\
Group II & $195.97 \pm 4.312$ & $180.48 \pm 4.320$ & $193.53 \pm 5.274$ & $178.77 \pm 4.290$ \\
Group III & $199.70 \pm 4.718$ & $186.23 \pm 4.319$ & $196.71 \pm 6.185$ & $184.36 \pm 4.568$ \\
\hline
\end{tabular}

*Mean pixel value from 9 animal samples.

${ }^{* *}$ Standard deviation for mean pixel from 9 animal samples. 

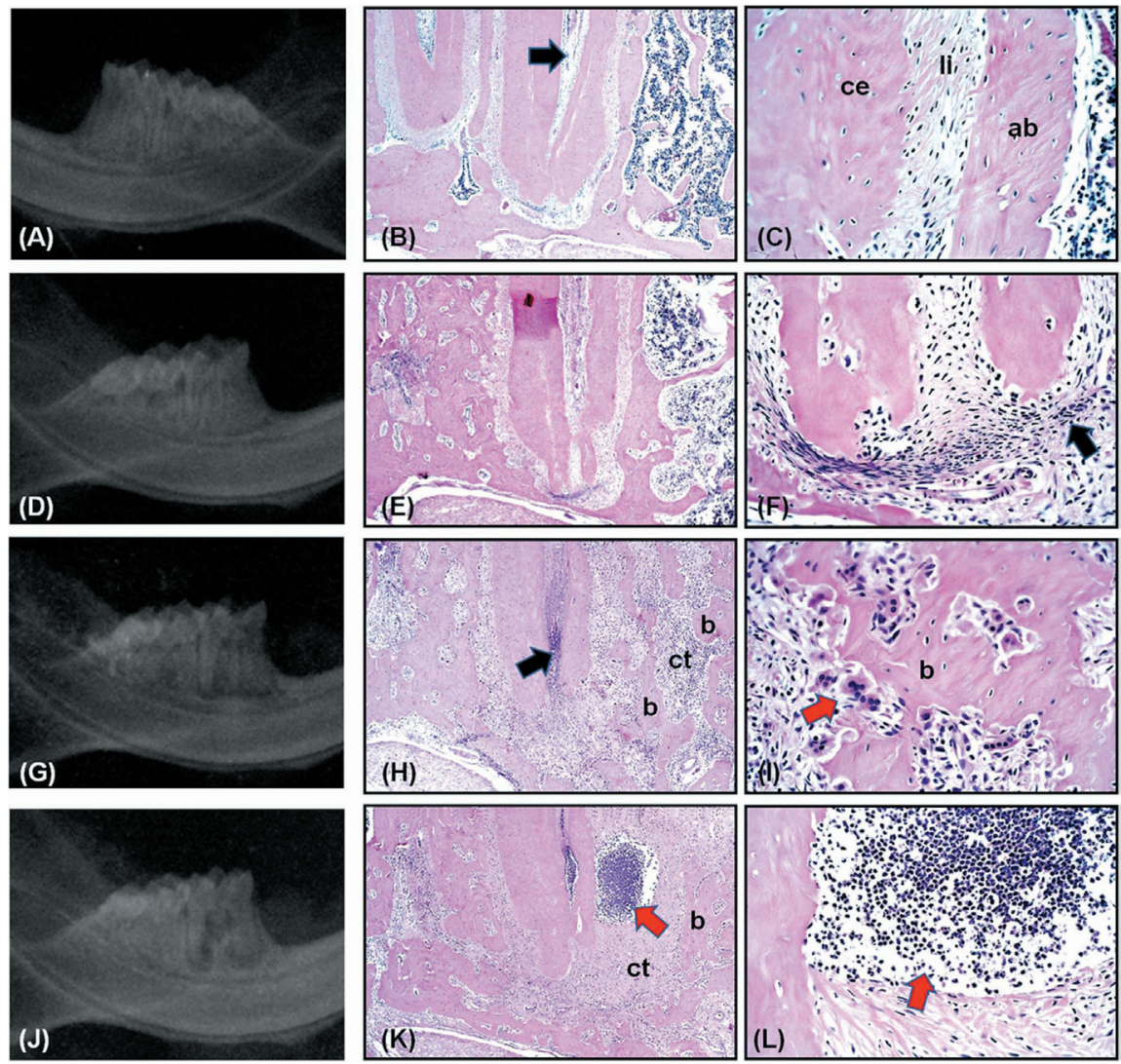

Figure 1- Control group: A) radiographic image of hemi-mandible; B-C) photomicrograph of the left first molar showing healthy pulp (black arrow) and periapical tissues with cementum (ce), fibers of periodontal ligament (li) and alveolar bone (ab). Group 1: D) radiographic image of hemi-mandible similar at the control group; E-F) photomicrograph of the right first molar exhibiting inflammatory cells (black arrow) in the periapical region. Group 2: G) radiographic image of hemi-mandible showing radiolucent area in the periapical region; $\mathrm{H}-\mathrm{l}$ ) photomicrograph of the right first molar showing extensive bone (b) resorption by osteoclasts (red arrow) and connective tissue (ct). Group 3: J) radiographic image of hemi-mandible exhibiting extensive radiolucent area in the periapical region; K-L) photomicrography of the right first molar showing abscess (red arrow), increase of connective tissue area (ct) and decrease of bone tissue (b) in relation to the other groups

Table 2- Mean and standard deviation of the total number of pixels of each structure present in the periapical region of the mesial root of the mandibular first molar in the control and test groups in the experimental periods

\begin{tabular}{lcccccc}
\hline & \multicolumn{3}{c}{ Histologic pixel values } & & & \\
GROUP I & \multicolumn{3}{c}{ GROUP II } & \multicolumn{2}{c}{ GROUP III } \\
Region & Control & Test & Control & Test & Control & Test \\
\hline \multirow{2}{*}{ Root } & $415.48^{*}$ & 410.28 & 394.58 & 318.24 & 414.23 & 284.29 \\
& $\pm 42.958^{* *}$ & \pm 45.078 & \pm 34.707 & \pm 44.579 & \pm 68.810 & \pm 22.345 \\
\hline Soft tissue & 215.71 & 295.46 & 207.28 & 696.98 & 205.14 & 806.63 \\
& \pm 28.582 & \pm 31.593 & \pm 20.498 & \pm 61.367 & \pm 32.021 & \pm 45.912 \\
\hline Bone tissue & 554.40 & 476.99 & 616.39 & 375.94 & 610.70 & 297.40 \\
\hline Bone marrow & \pm 35.857 & \pm 34.094 & \pm 11.7848 & \pm 33.248 & \pm 63.826 & \pm 41.971 \\
\hline Alveolar nerve & 211.70 & 208.89 & 176.63 & Absent & 169.99 & Absent \\
\hline
\end{tabular}

*Mean pixel value from 9 animal samples.

${ }^{* *}$ Standard deviation for mean pixel from 9 animal samples. 


\section{Histopathological analysis}

The histological analysis of the left first molars of the rats, which served as control, showed no alterations in the pulp or periapical tissues, and evidenced that $100 \%$ of these teeth presented healthy pulp and periapical tissues (Figures 1B, C). The teeth submitted to coronal opening in group 1 , showed in $100 \%$ of the cases, necrosis in the coronal region and pulp inflammation with the presence of inflammatory cells and increased vascularization in the medial and apical thirds. It was possible to observe inflammatory cells and small bone and cementum resorption in the periapical region (Figures 1E, F). Group 2 showed necrosis in the coronal and middle radicular pulp and extensive inflammatory process in the apical third. In the periapical region exhibited increase of bone resorption and replaced by conjunctive tissue rich in inflammatory cells (Figures $1 \mathrm{H}, \mathrm{I}$ ). The group 3 showed total pulp necrosis, extensive area of abscess and bone, cementum and dentine resorption and few bone trabeculae surrounded by conjunctive tissue in the apical portion (Figures $1 \mathrm{~K}, \mathrm{~L})$.

The area measured histomorphometrically was given in number of pixels. The total numbers of pixels obtained for each of the measured regions in the control and tests sides, in the various experimental periods are presented in Table 2. Twoway ANOVA and Tukey's tests showed statistically significant difference between the test and control sides and among the experimental periods as well.

\section{DISCUSSION}

In the present study, the periapical inflammation was induced by coronal opening of the mandibular right first molar and confirmed that only coronal opening and pulp contact with the oral cavity were sufficient for inducing periapical disease. Various other studies have described this technique for induction of pulpal and periapical inflammatory reactions in rat teeth ${ }^{19,28}$. The inflammatory process was observed in the pulp region in the experimental period of 2 days. This is in agreement with the findings of a previous study that showed that pulp inflammation is already observed $6 \mathrm{~h}$ after the operative procedure ${ }^{19}$. In the present study, pulp necrosis was observed in the experimental periods of 15 and 30 days. This is also in agreement with a previous study that showed the presence of complete pulp necrosis between the $8^{\text {th }}$ and $20^{\text {th }}$ days $^{27}$.

Hamachi, et al. ${ }^{16}$ (1995) affirmed that bone resorption is present from the $3^{\text {rd }}$ day after the operative procedure. Bone resorption in the present study, although very subtle, could already be observed in the Group 1. Resorptive bone activity was actively present on the $15^{\text {th }}$ day (Group 2 ). Some authors affirmed that this activity begins to diminish from then on, with a decrease in the number of osteoclasts $^{1}$. Although the lesion appeared to be stabilized, with diminished bone resorption, new bone formation did not occur due to the presence of aggressive factors ${ }^{30}$. In the 30-day experimental period, a large area of resorption could be observed, but a smaller number of osteoclasts were present. The amount of periapical bone was minimal, and it was replaced by inflammatory tissue.

Statistical analysis showed a significant difference between test and control sides in the 3 experimental periods, except for the root region, in which this difference was not significant between the test and control sides, in the 2-day period, and between the experimental periods of 15 and 30 days. This was probably because resorption in periapical disease is greater in the bone region than in the root region, which was not very evident.

The present study confirmed radiographically the presence and intensity of bone resorption observed by the histological study. Jett, et al. ${ }^{18}$ (2004) and Shrout, et al. ${ }^{26}$ (2003) removed medullar bone from cadaver mandibles, radiographed the areas to measure the pixel value respectively. These studies showed that it is possible to detect bone loss in the mandibular region by analyzing the pixel value, even if it is not yet visible radiographically. Conversely, studies that compared images obtained by conventional radiographs (without pixel value analysis) and bone resorption seen microscopically, showed that this relationship is not established with precision ${ }^{4,14}$,

De Rossi, et al. ${ }^{9}$ (2007) concluded that although image digitization could not improve the detection of the early stages of periapical lesions, it provides valuable quantitative assessment of extensive periapical lesions.

In order to diminish the noise level in the images captured directly, the phosphorus plates were covered by a protective envelope, as they are sensitive to light ${ }^{24}$. The images were always downloaded immediately after the radiograph was taken, as the time between taking the radiograph and downloading the plates also influences the pixel values ${ }^{5,13}$.

In the direct photostimulable phosphorus plate systems, such as Digora $^{\circledR}$, there is a correlation between the radiation dose and the quantity of capture plate luminescence ${ }^{11,20,22}$. The capture plates present less noise and a better quality image than the other direct systems, in addition to being more sensitive to small variations of the exposure source in comparison with conventional films, and should be used when small differences in contrast are important 17,20 . The noise and coefficient of variability of pixel value calculations showed low 
noise and small variation in the images in this study.

In spite of resistance by many professionals, the high cost of the technology and the ethical implications because of the risk of manipulating the images, the use of digital imaging has increased and is constantly being perfected. Computerization tends to make this one the method of choice for daily radiographs.

\section{CONCLUSIONS}

The methodology applied was efficient for causing pulpitis and pulpal necrosis in the studied rats. Teeth with pulpitis microscopically presented periapical bone resorption, but the teeth with necrosis presented greater resorption. The control teeth presented healthy pulp, without signs of periapical bone resorption. The means of the pixel values in the areas of periapical disease induced in rats indicated greater bone resorption than the means of these values on the control side for the three experimental periods $(p<0.05)$. Even small periapical bone resorption was already sufficient for determining changes in the pixel values of that area in the direct digital method, when compared to their respective controls.

\section{REFERENCES}

1- Anan H, Akamine A, Maeda K. An enzyme histochemical study of the behavior of rat bone cells during experimental apical periodontitis. J Endod. 1993;19:83-6.

2- Attaelmanan A, Borg E, Gröndahl HG. Digitisation and display of intra-oral films. Dentomaxillofac Radiol. 2000;29:97-102.

3- Balto K, Müller R, Carrington DC, Dobeck J, Stashenko P. Quantification of periapical bone destruction in mice by microcomputed tomography. J Dent Res. 2000;79:35-40.

4- Barkhordar RA, Hussain MZ, Hayashi C. Detection of interleukin-1 beta in human periapical lesions. Oral Surg Oral Med Oral Pathol. 1992;73:334-6.

5- Borg E, Attaelmanan A, Gröndahl HG. Image plate systems differ in physical performance. Oral Surg Oral Med Oral Pathol Oral Radiol Endod. 2000;89:118-24.

6- Camps J, Pommel L, Bukiet F. Evaluation of periapical lesion healing by correction of gray values. J Endod. 2004;30:762-6.

7- Cotti E, Vargiu P, Dettori C, Mallarini G. Computerized tomography in the management and follow-up of extensive periapical lesion. Endod Dent Traumatol. 1999;15:186-9.

8- Delano EO, Tyndall D, Ludlow JB, Trope M, Lost C. Quantitative radiographic follow-up of apical surgery: a radiometric and histologic correlation. J Endod. 1998;24:420-6.

9- De Rossi A, De Rossi M, Rocha LB, Silva LA, Rossi MA. Morphometric analysis of experimentally-induced periapical lesions: radiographic vs histopathological findings. Dentomaxillofac Radiol. 2007;36:211-7.

10- Farman AG, Avant SL, Scarfe WC, Farman TT, Green DB. In vivo comparison of Visualix-2 and Ektaspeed Plus in the assessment of periradicular lesion dimensions. Oral Surg Oral Med Oral Pathol Oral Radiol Endod. 1998;85:203-9.

11- Farrier SL, Drage NA, Newcombe RG, Hayes SJ, Dummer PM. A comparative study of image quality and radiation exposure for dental radiographs produced using a charge-coupled device and a phosphor plate system. Int Endod J. 2009;42:900-7.
12- Ferreira RI, Haiter-Neto F, Tabchoury CP, Paiva GA, Bóscolo FN. Assessment of enamel demineralization using conventional, digital, and digitized radiography. Braz Oral Res. 2006;20:114-9. 13- Freitas P, Yaedú RY, Rubira-Bullen IR, Escarpinati M, Vieira $M C$, Schiabel $H$, et al. Reproducibility of pixel values for two photostimulable phosphor plates in consecutive standardized scannings. Braz Oral Res. 2006;20:207-13.

14- Genvert H, Miller H, Burn CG. Experimental production of apical lesions of teeth in monkeys, and their relation to systemic disease. Yale J Biol Med. 1941;13:649-62.

15- Grecca FS, Leonardo MR, Silva LA, Tanomaru Filho M, Borges MA. Radiographic evaluation of periradicular repair after endodontic treatment of dog's teeth with induced periradicular periodontitis. J Endod. 2001;27:610-2.

16- Hamachi T, Anan H, Akamine A, Fujise O, Maeda K. Detection of interleukin-1 beta mRNA in rat periapical lesions. J Endod. $1995 ; 21: 118-21$.

17- Hildebolt CF, Fletcher G, Yokoyama-Crothers N, Conover GL, Vannier MW. A comparison of the response of storage phosphor and film radiography to small variations in X-ray exposure. Dentomaxillofac Radiol. 1997;26:147-51.

18- Jett S, Shrout MK, Mailhot JM, Potter BJ, Borke JL. An evaluation of the origin of trabecular bone patterns using visual and digital image analysis. Oral Surg Oral Med Oral Pathol Oral Radiol Endod. 2004;98:598-604.

19- Kakehashi S, Stanley HR, Fitzgerald RJ. The effects of surgical exposures of dental pulps in germ-free and conventional laboratory rats. Oral Surg Oral Med Oral Pathol. 1965;20:340-9.

20- Kashima I. Computed radiography with photostimulable phosphor in oral and maxillofacial radiology. Oral Surg Oral Med Oral Pathol Oral Radiol Endod. 1995;80:577-98.

21- Laux M, Abbott PV, Pajarola G, Nair PN. Apical inflammatory root resorption: a correlative radiographic and histological assessment. Int Endod J. 2000;33:483-93.

22- Lim KF, Loh EEM, Hong HY. Quantitative assessment of a new intra-oral digital imaging system. J Dent Res (Sp. Iss.). 1995; 74:463.

23- Marmary $Y$, Koter T, Heling I. The effect of periapical rarefying osteitis on cortical and cancellous bone. A study comparing conventional radiographs with computed tomography. Dentomaxillofac Radiol. 1999;28:267-71.

24- Rubira-Bullen IRF, Escarpinati MC, Schiabel H, Vieira MAC, Rubira CMF, Lauris JRP. Evaluating noise in digitized radiographic images by means of histogram. J Appl Oral Sci. 2006;14:410-4. 25- Schmitd LB, Lima TC, Chinellato LEM, Bramante CM, Garcia RB, Moraes IG, et al. Comparison of radiographic measurements obtained with conventional and indirect digital imaging during endodontic treatment. J Appl Oral Sci. 2008;16:167-70

26- Shrout MK, Jett S, Mailhot JM, Potter BJ, Borke JL, Hildebolt CF. Digital image analysis of cadaver mandibular trabecular bone patterns. J Periodontol. 2003;74:1342-7.

27- Stahl SS. Response of the periodontium, pulp, and salivary glands to gingival and tooth injury in young adult male rats. II. Pulp and periapical tissues. Oral Surg Oral Med Oral Pathol. 1960;13:734-42.

28- Tagger M, Massler M. Periapical tissue reactions after pulp exposure in rat molars. Oral Surg Oral Med Oral Pathol. 1975;39:304-17.

29- Tosoni GM, Lurie AG, Cowan AE, Burleson JA. Pixel intensity and fractal analyses: detecting osteoporosis in perimenopausal and postmenopausal women by using digital panoramic images. Oral Surg Oral Med Oral Pathol Oral Radiol Endod. 2006;102:235-41. 30- Wang CY, Stashenko P. Characterization of bone-resorbing activity in human periapical lesions. J Endod. 1993;19:107-11. 